\section{UAV-based Tree Height Estimation in Dense Tropical Rainforest Areas in Ecuador and Brazil}

Gl_Forum 2019, Issue 2 Page: 47 - 59 Short Paper Corresponding Author: stefan.reder@hnee.de DOI: 10.1553/giscience2019_02_s47

\author{
Stefan Reder, Lilli Waßermann and Jan-Peter Mund \\ Eberswalde University for Sustainable Development, Germany
}

\begin{abstract}
The aim of this study was to develop an easily applicable, cost-efficient workflow for tree height estimation in remote, inaccessible rainforest areas in Ecuador and Brazil. Structure from Motion (SFM) was combined with a digital terrain model (DTM) from the Shuttle Radar Topography Mission (SRTM) to complement relief information from photogrammetric point clouds (PPC) which represent the upper canopy layers. Based on ground points extracted from a 3D model, a vertical shift of the model was applied to adjust the ellipsoid level of the PPC. Digital surface models (DSM) of 22 research plots were normalized to canopy height models (CHM) to allow the estimation of relative tree heights in all research plots without using ground control points (GCP). The calculated tree height values indicate the applicability of the proposed workflow even in tropical rainforests with dense canopies. This approach allows the classification of canopy structures for identifying forest succession and other ecological forest monitoring purposes. The results highlight the potential of 3D models for tree height estimation derived from PPCs based on unmanned aerial vehicle (UAV) imagery in rainforest research.
\end{abstract}

\title{
Keywords:
}

unmanned aerial vehicle (UAV), rainforest, canopy height model (CHM), structure from motion (SfM), forest structure

\section{Abbreviations used in the text:}

AGL Altitude Above Ground Level

ASL Altitude Above Sea Level

CHM Canopy Height Model

DTM Digital Terrain Model

ECP Elevation Correction Point

GCP Ground Control Point

GSD Ground Sampling Distance

LIDAR Light Detection and Ranging

PPC Photogrammetric Point Cloud

SFM Structure from Motion

SRTM Shuttle Radar Topography Mission

UAV Unmanned Aerial Vehicle

USGS United States Geological Survey 


\section{Introduction}

There is a vast range of applications in tropical rainforest research, where the estimation of tree heights and the modelling of canopy structures and its surface are urgent. The canopy height is an important factor for estimating biomass (Hunter, Keller, Victoria, \& Morton, 2013). Tree heights serve as an indicator for the state of succession and condition of the forest ecosystem, as the average tree height in primary forests is higher than in secondary forests (Richards \& Walsh, 1996). Additionally, the height variations along the canopy surface increase constantly and are greater in the later stages of succession (Birnbaum, 2001). Furthermore, a canopy height model (CHM) can be used for spatial analyses of forest dynamics, such as gap formations and regrowth (Birnbaum, 2001). Canopy models are used to investigate the light regime, which regulates seedling regeneration (Montgomery \& Chazdon, 2001). Moreover, height variations along the canopy can be used to calculate a vegetation roughness index for the creation of atmosphere-land interaction models (Raupach, 1994). The structural diversity of the canopy can also be used as an indicator for biodiversity (Lindenmayer, Margules, \& Botkin, 2000).

In accessible forests and forest plantations, tree height measurements are typically made from the ground using ultrasound or hand-held laser measurement tools (Thünen - Institute of Forest Ecosystems, 2017). This manual technique has at best an accuracy of $0.2 \mathrm{~m}$ (Vasilescu, 2013). A terrestrial laser scanner provides good results, but has a tendency towards underestimation (Olofsson, Holmgren, \& Olsson, 2014). But for the application of these tools, the forest needs to be accessible. Light detection and ranging (LIDAR) provides another sophisticated, but expensive, technological alternative for measuring exact tree heights and is frequently applied in temperate forests. Technically, this is a reasonable solution which produces precise results with a mean elevation error of less than $0.2 \mathrm{~m}$, but it is only costefficient for large areas (Cao et al., 2019; Leitold, Keller, Morton, Cook, \& Shimabukuro, 2015).

Consumer cameras mounted on unmanned aerial vehicles (UAV) equipped with autonomous flight management software can produce very high resolution imagery with a ground resolution of less than $0.5 \mathrm{~cm}$ and a high image overlap that allows the calculation of $3 \mathrm{D}$ point cloud models using structure from motion (SfM) (Krause, Sanders, Mund, \& Greve, 2019). In combination with ground control points (GCPs), canopy heights and even individual tree heights can be extracted easily from 3D point clouds with an accuracy similar to LIDAR measurements (Krause et al., 2019; Torres-Sánchez, López-Granados, Serrano, Arquero, \& Peña, 2015).

\section{Motivation, Aim and Scope of the Study}

In this paper, we present a robust and easily applicable solution for tropical tree height estimation in dense and remote, or even inaccessible, rainforest areas, where using GCPs or additional ground truth surveys is expensive, dangerous or even impossible (see section 3). The aim of the study was to find ways to extract relative individual tree heights and structural differences in the canopy and crown surface which can be used to characterize and/or classify forest succession under various conditions. Another aim was to evaluate options for rainforest 
monitoring, using UAV imagery, in order to facilitate protection management. The workflow has the advantage of being usable by NGOs or volunteers without access to sophisticated survey and image processing equipment.

\section{Material and Methods}

The data for this study was collected on 22 investigation plots in the evergreen rainforest along the foothills of the Ecuadorian Andes (9 plots), and the evergreen Atlantic Mountain Rainforest in Brazil (13 plots). In order to get access to such remote, dense, tropical forest plots, we cooperated with two NGOs, the Asociación Lisan Yacu Iloculin (Centro de Educación Ambiental en el Ecosistema Amazónico) in Ecuador, and the Entidade Ambientalista Onda Verde in Brazil. As we intended to develop a workfow that can also be applied by NGOs and volunteers, which typically have less funding, the research was restricted to a low-budget investigation.

From October 2017 to March 2018, we conducted an applied-science research project, aiming for a structural analysis of the canopies of selected small-sized tropical-rainforest plots in Ecuador and Brazil. The location of these areas can be seen in Figure 1.

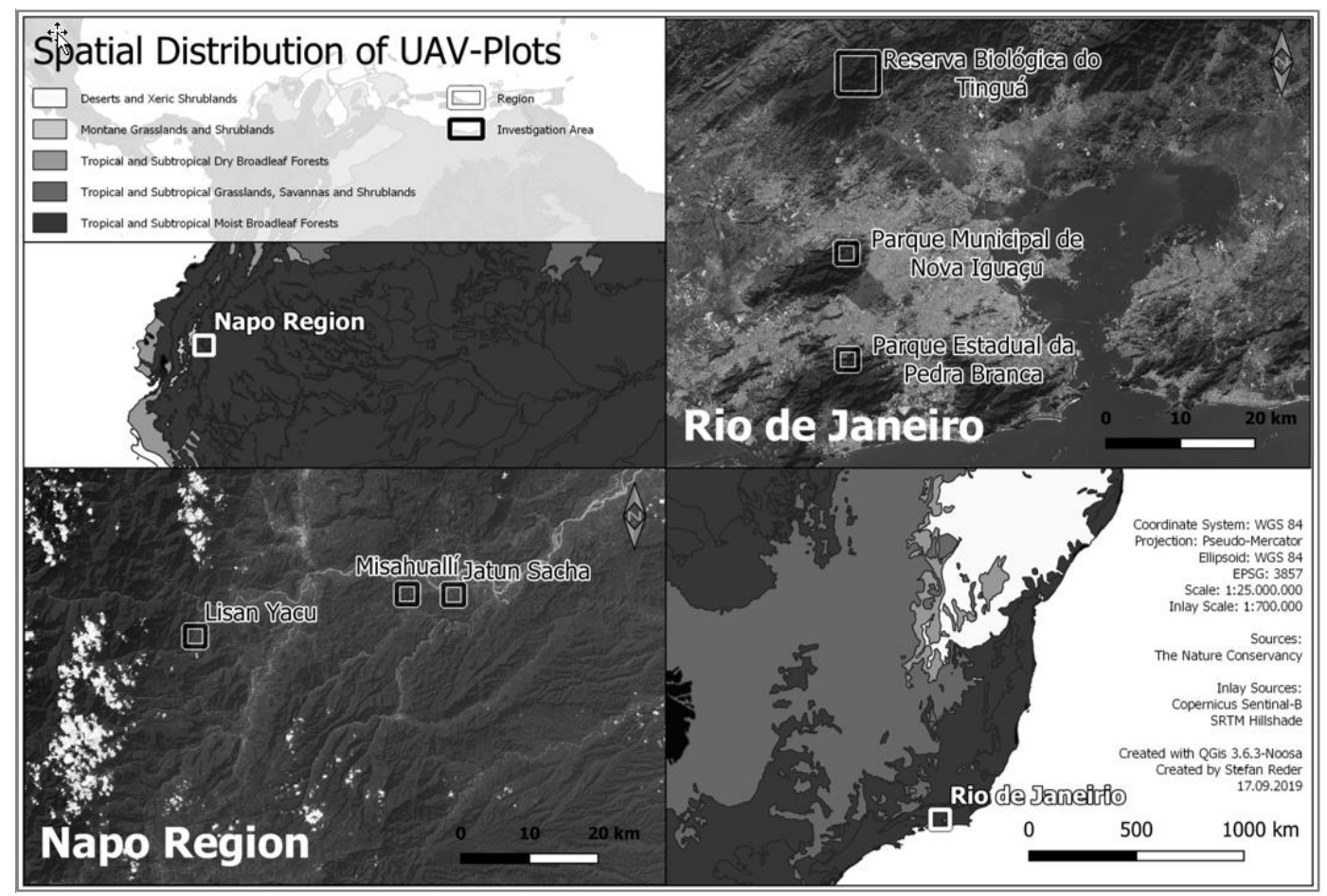

Figure 1: Maps of the investigation sites in Ecuador (left) and Brazil (right), and a map of the ecoregions of Latin America (background) 
In Ecuador, the investigation areas were chosen in the Napo region, $20 \mathrm{~km}$ south-east of the regional capital Tena, close to the River Napo in the foothills of the Andes. The ecosystem in this area is classified as Amazon lowland evergreen rainforest and is a biodiversity hotspot (Sierra, Campos, \& Chamberlin, 2002). In Brazil, the plots were in the state of Rio de Janeiro, in three natural reserves. These reserves are all found in the Mata Atlântica, a coastal tropical forest classified as Floresta Ombrófila (IBAMA, 2006) which contains many hotspots of endemic species and is in great danger of being deforested (Crouzeilles, Feltran-Barbieri, Ferreira, \& Strassburg, 2017). The plots were chosen for the state of succession they manifested since the last large-scale disturbance occurred (e.g. clear cutting or storm clearing), namely early succession (< 50 years), late succession (> 50 years), and climax/old growth $>$ 100 years). Information about the plots' histories was obtained from oral and/or other evidence.

The data collection was restricted by the limited accessibility and dense structure of the rainforest and thus had to be adapted to the conditions. Reaching the primary forest by car with large and sophisticated equipment was not always possible as roads do not exist in most of the areas investigated. Often, access can be gained only on foot over long distances through difficult terrain, requiring all technical equipment and several days' worth of food and other provisions to be carried into the forest. Untouched or intact dense rainforest remains are often found only on steeper slopes or in other remote areas. They are thus difficult and dangerous or even impossible to access (Porembski \& Barthlott, 2000). The majority of the research plots were not accessible on foot but could be reached by UAV automatic image acquisition flights.

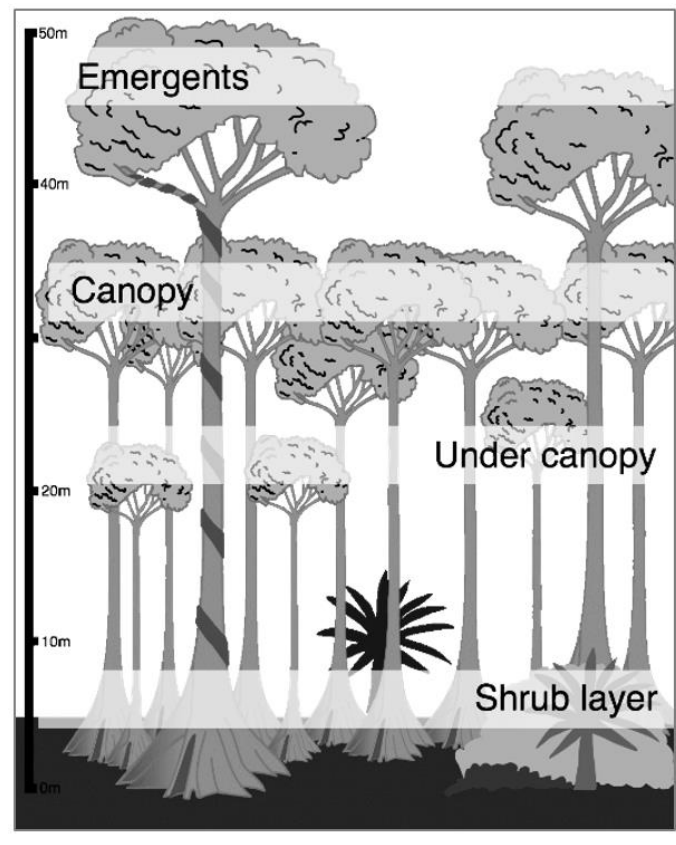

\section{Figure 2:}

Canopy structure of dense rainforests Source: https://www.internetgeography.net/topics/wha t-is-the-structure-of-the-tropical-rainforest/ 
In general, tropical rainforests have very dense canopy and under-canopy layers, as illustrated in Figure 2. Only 1\% to 2\% of the canopy is opened by treefalls each year (Brokaw, 1985), and as the competition for light is very strong, small gaps close in 3 to 6 years. Even in cases of larger openings $\left(>300 \mathrm{~m}^{2}\right)$, a new closed canopy layer with a height of $10 \mathrm{~m}$ generally takes just 5-10 years to become established (van der Meer, 1995). Therefore, in such dense and multilayered canopies it is rare to find openings or canopy gaps which reach to the ground and are large enough to install GCPs and calculate differential GNSS-positions, as the vegetation strongly influences the signal. Furthermore, it is impossible to extract the requisite number of ground points from the 3D model to calculate a digital terrain model (DTM) (Wallace, Lucieer, Malenovský, Turner, \& Vopěnka, 2016). Using traditional forest mensuration equipment such as mobile laser or a Vertex under this type of canopy structure leads to uncertainty in tree height measurements from the ground, because generally speaking the treetops are not visible (Larjavaara \& Muller-Landau, 2013).

Taking all these restrictions and limitations into account, then, traditional, common or very sophisticated surveying methods for tree height measurements were excluded from this research. We therefore decided to develop a simple but still state-of-the-art and repeatable approach for tree height estimations in dense rainforests. This approach is based on UAV imagery and photogrammetric point clouds, and it works without surveyed GCPs. This aims to estimate relative tree and canopy heights and to describe relative changes in canopy structure in order to distinguish categories such as degraded, secondary or primary rainforest types. Thus, the principal aim is the estimation of stand heights or the mean heights of the upper and/or different canopy layers, rather than the precise measurement of the exact height of individual trees. This method is not intended for application in high-precision forestry or tree measurements for economic timber calculations.

\subsection{UAV-based data collection}

A DJI Mavic Pro commercial drone was used to capture images for the calculation of $3 \mathrm{D}$ point cloud models. The inbuilt camera has a 1/2.3" CMOS sensor and captures Red Green Blue (RGB) pictures in 4k resolution (4,000 x 3,000 pixels) (DJI, 2017).

For each investigation plot, an area of $75 \mathrm{~m} \times 75 \mathrm{~m}$ was demarcated on the flight plan; three automatic flight plans (Pix4D Capture App Version 3.8) per plot were carried out to capture the canopy structure. The flight plan settings are shown in Table 1 . After an initial investigative flight to identify the tallest tree within each research plot, the flight altitude was set to $30 \mathrm{~m}$ above the canopy. All three flights per plot were then flown at the same height, which, depending on the canopy height, resulted in an altitude above ground level (AGL) of $60 \mathrm{~m}$ to $100 \mathrm{~m}$ and an average ground sampling distance (GSD) of $2 \mathrm{~cm}$. The camera was fixed at a different angle for each of the three flights per plot. The views from different camera incident angles on the canopy and its gaps and openings allow a detailed reproduction of the canopy structure in a later data fusion stage. This also allows the visualization of parts of the undercanopy layers, the ground vegetation and the ground surface which are not visible in nadir flights. The first flight was a single nadir flight, with 95\% image overlap. The second and third flights were both cross flight plans, with $85 \%$ image overlap and oblique camera angles of $60^{\circ}$ and $30^{\circ}$. Through iterative testing, this combination of camera angles proved to give valuable 
results. The data collection workflow was tested and assessed beforehand in mixed forest stands with various canopy structures in Brandenburg, where exact tree heights are available for comparison (Krause et al., 2019).

Table 1: Automated flight plan settings applied for each of the 22 research plots in Ecuador and Brazil

\begin{tabular}{|l|l|l|l|l|l|l|}
\hline $\begin{array}{l}\text { Plot } \\
\text { Size }\end{array}$ & Flight plan & $\begin{array}{l}\text { Camera } \\
\text { angle }\end{array}$ & $\begin{array}{l}\text { Image } \\
\text { overlap }\end{array}$ & Flight speed & $\begin{array}{l}\text { Height above } \\
\text { canopy }\end{array}$ & $\begin{array}{l}\text { GSD } \\
\text { average }\end{array}$ \\
\hline & $1 \times$ nadir & $90^{\circ}$ & $95 \%$ & $\sim 2 \mathrm{~m} / \mathrm{s}$ & $30 \mathrm{~m}$ & $2 \mathrm{~cm}$ \\
\hline $\mathbf{7 5} \mathbf{m} \times \mathbf{7 5}$ & $\begin{array}{l}1 \times \text { cross } \\
\text { oblique }\end{array}$ & $60^{\circ}$ & $85 \%$ & $\sim 4 \mathrm{~m} / \mathrm{s}$ & $30 \mathrm{~m}$ & $2 \mathrm{~cm}$ \\
\hline & $\begin{array}{l}1 \times \text { cross } \\
\text { oblique }\end{array}$ & $30^{\circ}$ & $85 \%$ & $\sim 4 \mathrm{~m} / \mathrm{s}$ & $30 \mathrm{~m}$ & $2 \mathrm{~cm}$ \\
\hline
\end{tabular}

\subsection{Data processing}

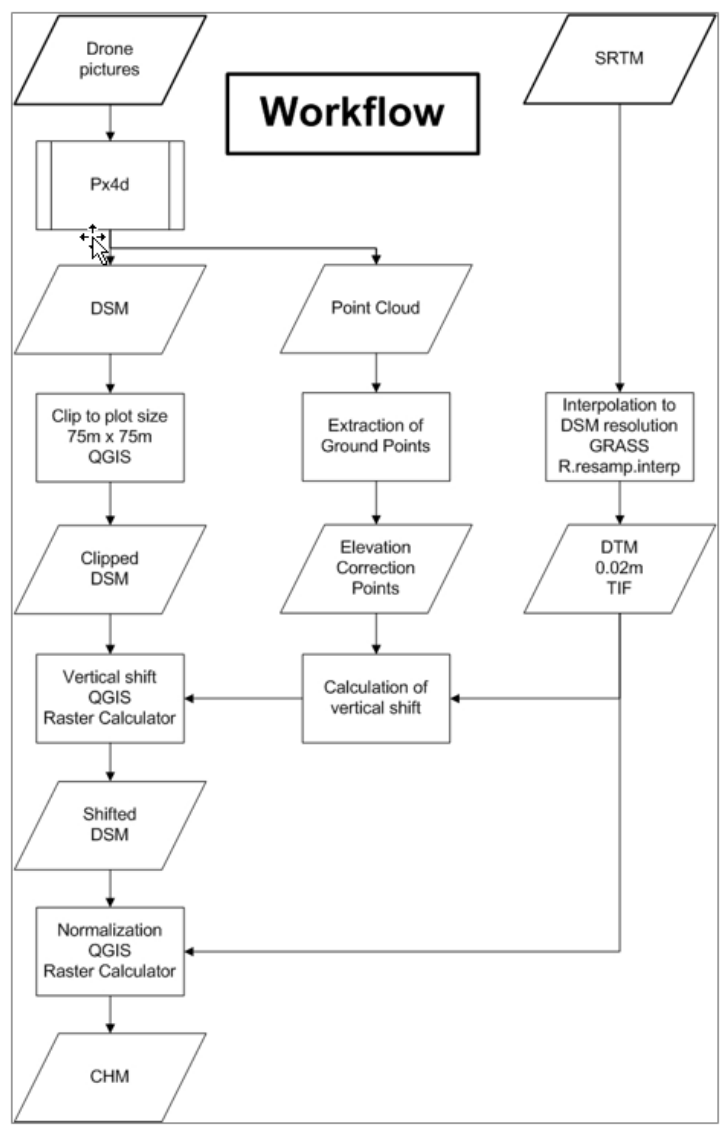

Figure 3: Workflow diagram for the calculation of a CHM from UAV images and an external DTM 
In this section, the image- and data-processing workflow is described (and illustrated in Figure 3). We decided to use the Pix4D Desktop App Version 4.1.25 for calculating the 3D point cloud model. Even though the cost of professional proprietary software is high, the technical and application advantages are better than those of open source packages such as OpenDroneMap (Alidoost \& Arefi, 2017).

In order to generate ground points, especially beyond tree crowns and in narrow canopy openings, the pictures from the three individual flights were processed together. For this scenario, the standard settings of the template for 3D models had to be adapted. To improve the calculation of the camera positions, Triangulation of Image Geolocation was used for Matching in the Initial Processing stage. The Relative Distance Between Consecutive Images was increased to eight to force the algorithm to search for matching points in eight neighbouring images in each direction. This increases the calculation time but enables the program to find matching points between nadir and oblique flights.

In addition, the Geometrically Verified Matching was activated for more precise matching in a relatively homogeneous colour spectrum, as found in green forests (Pix 4D, 2018). The outputs are a photogrammetric point cloud (PPC), an Orthophoto and the digital surface model (DSM). The DSM shows the altitudes above sea level (ASL) of the canopy surface.

As the PPCs did not provide sufficient ground points to generate a DTM, the information about the ground surface structure had to be supplemented from an external source. To meet typical NGO constraints such as lack of expert knowledge and need for a low-budget workflow, the ASL of each research plot was taken from the Shuttle Radar Topography Mission (SRTM), which is provided free of charge by the United States Geological Survey (USGS). It has a sampling distance of 1 arc sec, which corresponds to approximately $30 \mathrm{~m}$ per pixel (Kautz, 2017). As preparation for the normalization, it had to be interpolated to the resolution of the DSM.

Several technical and surveying problems had to be solved in the course of this process.

In dense forest areas, radar techniques, such as those used by the SRTM, are known to represent the surface of the vegetation layer rather than the bare ground (Gesch, J. Oimoen, \& A. Evans, 2014). The above-ground height information stored in the Exchangeable Image File Format header (Exif) of UAV images is given as ASL, as the GPS AltitudeRef flag indicates (Camera \& Imaging Products Association, 2010). Thus, UAV altitudes refer to the WGS84ellipsoid, while altitudes calculated in the SRTM refer to the EGM96-geoid (Kautz, 2017), which requires a 3D re-projection to adjust the z-level accordingly.

To remove this difference between the geodic and ellipsoid heights and the vertical error from the SRTM, a vertical shift of the $z$-coordinate was applied. Therefore, at least 3 ground points in each PPC, referred to from now on as ECPs (elevation correction points), were manually identified as ground references.

Subsequently, the differences between the elevation of each ECP and the elevation of the corresponding $\mathrm{x} / \mathrm{y}$-coordinate in the DTM were calculated as follows. The mean of the differences equals the vertical shift. 
vertical shift $=\frac{\sum(z(S R T M)-z(P P C))}{n}$; with $\mathrm{z}=$ elevation, $\mathrm{n}=$ number of ECPs

In the following step, the DSM was vertically shifted with the Raster Calculator in the QGIS program as follows:

$$
D S M_{\text {shifted }}=D S M+\text { verical shift }
$$

The shifted DSM was then normalized using the QGIS Raster Calculator. The result is a CHM, which shows the elevation of the canopy surface above forest ground.

$$
C H M=D S M_{\text {shifted }}-D T M
$$

The intermediate outputs and the result of the workflow are visualized in Figure 4.
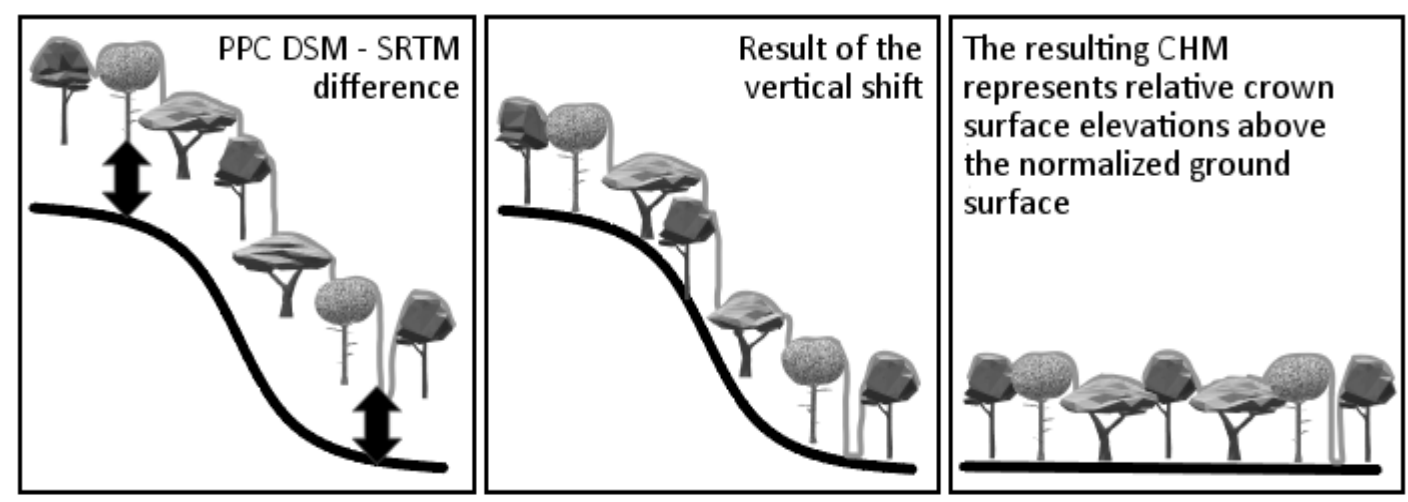

Figure 4: Conceptual illustration of workflow results; left: the DSM, generated in Pix4D, showing ungrounded vegetation layer; middle: after the application of the vertical shift, all trees are grounded to the surface; right: the normalization generates the $\mathrm{CHM}$, which represents the relative elevation of the crown surface above the ground surface

\section{Results}

\subsection{Example Pedra Branca 0301 Plot 3}

The research plot Pedra Branca 0301 Plot 3 is located in Brazil, south-west of Rio de Janeiro city, in the Mata Atlântica, on a $25^{\circ}$ slope. It will be used as an example of the analytical results for the 22 individual research plots.

The original DSM derived from the PPC showed height values of $850 \mathrm{~m}$ to $910 \mathrm{~m}$ and was levelled completely under the surface of the SRTM. ECP 50 and ECP 52 were visible in canopy gaps below the crown surface and could only be detected in the PPC due to matching points derived from pictures taken during oblique camera flights.

The mean height difference between the three ECPs and the SRTM resulted in a relative vertical shift of $+23 \mathrm{~m}$. The shifted DSM and the DTM are shown at the top of Figure 5. 


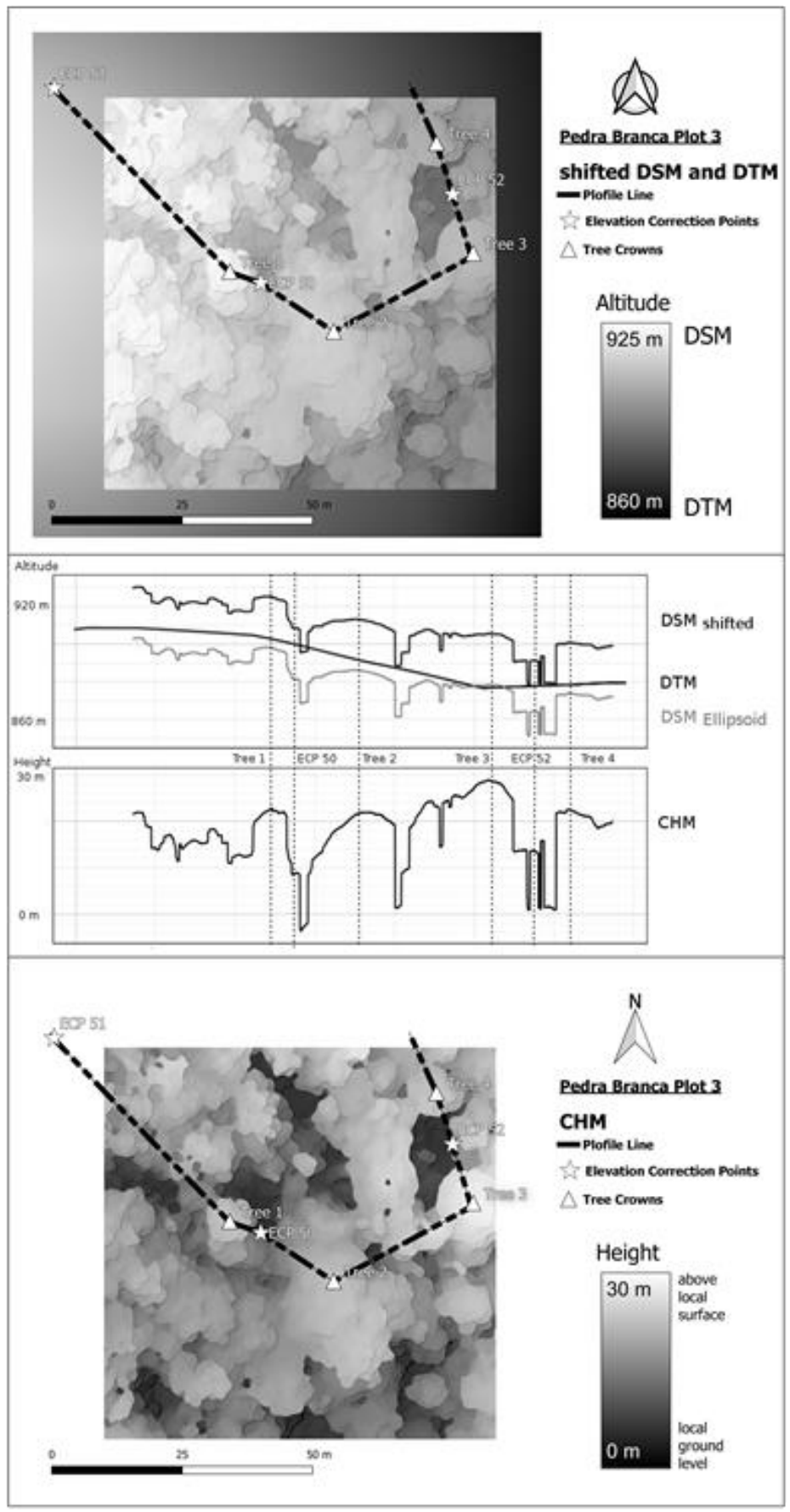

Figure 5: Results of Pedra Branca Plot 3; top: Visualization of the shifted DSM, the DTM and the transect for the profile view that follows the ECPs and selected treetops; middle: Profile view of the DSM before and after the shift with the resulting normalized $\mathrm{CHM}$; bottom: Visualization of the $\mathrm{CHM}$ with the derived crown surface height. 
A profile view was calculated that followed the dashed black line connecting the tallest treetops and the ECPs (Figure 5, middle). This profile shows that the lowest PPC points of the shifted surface model are located close to the terrain model. The highest treetop along the cutline is estimated to be $29 \mathrm{~m}$, while the height of most trees in the upper canopy of this $75 \mathrm{~m} \mathrm{x} 75 \mathrm{~m}$ plot is estimated to be $25 \mathrm{~m}$ AGL.

As a result of the normalization, the CHM (Figure 5, bottom) shows only a few areas with a negative value. The analysis of the CHM revealed a mean value of $15.7 \mathrm{~m}$ with a standard deviation of $6.8 \mathrm{~m}$, while the highest point of the canopy is $29.7 \mathrm{~m}$ above and the lowest point $4.8 \mathrm{~m}$ below the interpolated surface. This tree height estimation based on DTM, DSM and a normalized CHM was applied identically to all the other 21 research plots. The results of the statistical analysis are presented in section 4.2.

\subsection{Statistical Analyses}

Grouping all observed plots by their state of succession, the maximum values of the CHM indicate taller trees in a later state of succession (Figure 6). The median of the plots of the forest climax group is, at $39 \mathrm{~m}$, much higher than the median of the secondary forest plots in early or late succession (33 m and $31 \mathrm{~m}$ respectively). Degraded plots show significantly lower estimated tree heights, with a median height of $14 \mathrm{~m}$. While there is little difference between the median heights in early and late-secondary succession plots, the ranges of the height values of the plot groups show a clear tendency towards taller trees in the later successional stage.

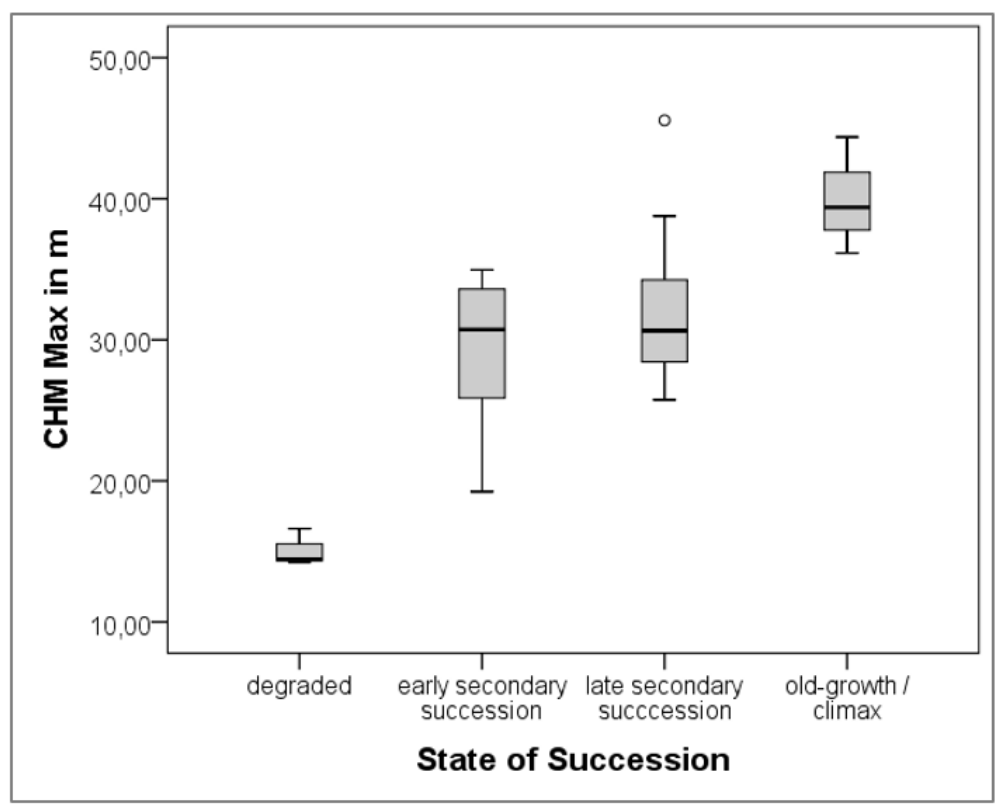

Figure 6: The boxplots show the maximum values of the CHM grouped by the state of succession. (Early succession < 50 y; late succession 50 - 100 y; old-growth / climax > 100 y) 


\section{Discussion and conclusion}

This study demonstrates the feasibility of estimating tree height values for dense as well as degraded rainforest plots from UAV imagery, without using GCPs as further ground level reference. A combination of nadir and oblique flight plans with differing incident camera angles offer insights, even for very dense multi-layered forest areas, into the derived PPCs for the extraction of ECPs. The increased density of matching points, as a result of combining pictures from all three flights (oblique flights of $60^{\circ}, 30^{\circ}$ and nadir), allowed the $3 \mathrm{D}$ matching and visualization of forest structures which are not visible in simple nadir DSM or CHM. Furthermore, the statistical evaluation indicates that the succession states can be distinguished from the estimated heights. With these results, our approach helps to close a gap in rainforest canopy research. Until now, there have been no satisfactory means for low-cost and remote succession analyses, as freely available satellite data does not provide sufficient resolution (Chazdon, 2014), while other approaches rely on LIDAR and ground surveys (Almeida et al., 2019) which are unaffordable for local NGOs (see section 2). Nonetheless, the model makes several assumptions which must be tested and verified before reliable statements about the accuracy of the 3D point cloud data can be drawn. First, the 3D PPC model itself is coherent internally, but we cannot guarantee its accuracy: we worked without GCPs, and therefore scaling problems with modelled pixel sizes and their exact location in the 3D point cloud remain. Second, the ECPs used to correct the CHM were chosen manually from the PPC. In this manual workflow, the correct selection of the lowest relative height detected for the representation of the local ground level is not guaranteed. Dense ground vegetation such as the herbal or shrub layer could be misidentified as ground level, which might result in an underestimation of local tree heights.

The study serves as proof of concept for the proposed UAV-based PPC workflow under typical NGO conditions and for other applied-science research with limited budget and access to sophisticated survey equipment. Although we were not able to verify the exact measurements of absolute tree heights on the plots, the methodology for analysing canopy reconstruction and estimating tree heights can be used in research into the ecological and successional status of other rainforest plots. 


\section{References}

Alidoost, F., \& Arefi, H. (2017). Comparison of UAS-Based Photogrammetry Software for 3D Point Cloud Generation: A Survey Over a Historical Site. ISPRS Annals of Photogrammetry, Remote Sensing and Spatial Information Sciences, IV -4 W4, 55-61. https://doi.org/10.5194/isprs-annals-IV-4-W4-552017

Almeida, D.R.A., $\quad$ Stark, S. C., $\quad$ Chazdon, R. $\quad$ [R.], $\quad$ Nelson, B. W., $\quad$ Cesar, R. G., $\quad$ Meli, P., Brancalion, P.H.S. (2019). The effectiveness of lidar remote sensing for monitoring forest cover attributes and landscape restoration. Forest Ecology and Management, 438, 34-43. https://doi.org/10.1016/j.foreco.2019.02.002

Birnbaum, P. (2001). Canopy surface topography in a French Guiana forest and the folded forest theory. Plant Ecology, 153(1/2), 293-300. https://doi.org/10.1023/A:1017563809252

Brokaw, N. V.L. (1985). Treefalls, Regrowth, and Community Structure in Tropical Forests. In S. T. Pickett \& P. S. White (Eds.), The ecology of natural disturbance and patch dynamics (pp. 53-69). Orlando, Florida: Academic Press. https://doi.org/10.1016/B978-0-08-050495-7.50009-0

Camera \& Imaging Products Association (2010). CIPA DC-008-2012: Exchangeable image file format for digital still cameras: Exif Version 2.3 (English). Retrieved from

http://www.cipa.jp/std/documents/j/DC-008-2012_J.pdf

Cao, L., Liu, H., Fu, X., Zhang, Z., Shen, X., \& Ruan, H. (2019). Comparison of UAV LiDAR and Digital Aerial Photogrammetry Point Clouds for Estimating Forest Structural Attributes in Subtropical Planted Forests. Forests, 10(2), 145. https://doi.org/10.3390/f10020145

Chazdon, R. L. [Robin L.]. (2014). Second Growth: The Promise of Tropical Forest Regeneration in an Age of Deforestation. Chicago: University of Chicago Press. Retrieved from http://gbv.eblib.com/patron/FullRecord.aspx?p=1676710

Crouzeilles, R., Feltran-Barbieri, R., Ferreira, M. S., \& Strassburg, B. B. N. (2017). Hard times for the Brazilian environment. Nature Ecology \& Evolution, 1(9), 1213. https://doi.org/10.1038/s41559-0170303-7

DJI (2017). Mavic Pro user manual 1.4. Retrieved from https://dl.djicdn.com/downloads/mavic/20170301/UserManual/Mavic_Pro_User_Manual_en_v 1.4.pdf

Gesch, D., J. Oimoen, M., \& A. Evans, G. (2014). Accuracy Assessment of the U.S. Geological Survey National Elevation Dataset, and Comparison with Other Large-Area Elevation Datasets-SRTM and ASTER. Retrieved from https://pubs.er.usgs.gov/publication/ofr20141008

Hunter, M. O., Keller, M., Victoria, D., \& Morton, D. C. (2013). Tree height and tropical forest biomass estimation, 10, 8385-8399. Retrieved from www.biogeosciences.net/10/8385/2013/

IBAMA (2006). Plano de Manejo Rebio do Tinguá. Retrieved from www.icmbio.gov.br/portal/images/stories/imgs-unidades-coservacao/rebio_tingua.pdf

Kautz, Sheila (2017). Shuttle Radar Topography Mission (SRTM) 1 Arc-Second Global. https://doi.org/10.5066/F7PR7TFT

Krause, S., Sanders, T. G.M., Mund, J.-P., \& Greve, K. (2019). UAV-Based Photogrammetric Tree Height Measurement for Intensive Forest Monitoring. Remote Sensing, 11(7), 758. https://doi.org/10.3390/rs11070758

Larjavaara, M., \& Muller-Landau, H. C. (2013). Measuring tree height: a quantitative comparison of two common field methods in a moist tropical forest. (4), 793-801.

Leitold, V., Keller, M. [Michael], Morton, D. C. [Douglas], Cook, B. D., \& Shimabukuro, Y. E. (2015). Airborne lidar-based estimates of tropical forest structure in complex terrain: Opportunities and trade-offs for REDD+. Carbon Balance and Management, 10(1), 3. https://doi.org/10.1186/s13021015-0013-x 
Lindenmayer, D. B., Margules, C. R., \& Botkin, D. B. (2000). Indicators of Biodiversity for Ecologically Sustainable Forest Management. Conservation Biology, 14(4), 941-950. https://doi.org/10.1046/j.1523-1739.2000.98533.x

Montgomery, R. A., \& Chazdon, R. L. (2001). Forest structure, canopy architecture, and light transmittance in tropical wet forests. Ecology, 82(10), 2707-2718.

Olofsson, K., Holmgren, J., \& Olsson, H. (2014). Tree Stem and Height Measurements using Terrestrial Laser Scanning and the RANSAC Algorithm. Remote Sensing, 6(5), 4323-4344. https://doi.org/10.3390/rs6054323

Pix4D (2018). Pix4dmapper 4.1 User Manual. Retrieved from https://support.pix4d.com/hc/enus/articles/205433155-Menu-Process-Processing-Options-1-Initial-Processing-Matching

Porembski, S., \& Barthlott, W. (2000). Inselbergs. Biotic Diversity of Isolated Rock Outcrops in Tropical and Temperate Regions (Vol. 146). https://doi.org/10.1007/978-3-642-59773-2

Raupach, M. R. (1994). Simplified expressions for vegetation roughness length and zero-plane displacement as functions of canopy height and area index. Boundary-Layer Meteorology, 71(1-2), 211216. https://doi.org/10.1007/BF00709229

Richards, P. W., \& Walsh, R. P. D. (1996). The tropical rain forest: An ecological study (2. ed.). Cambridge

Sierra, R., Campos, F., \& Chamberlin, J. (2002). Assessing biodiversity conservation priorities: ecosystem risk and representativeness in continental Ecuador. Landscape and Urban Planning, 59(2), 95-110. https://doi.org/10.1016/S0169-2046(02)00006-3

Thünen - Institute of Forest Ecosystems. (2017). Die dritte Bundeswaldinventur BWI 2012: Inventur-und Auswertungsmethoden. Eberswalde: Bundesministerium für Ernährung und Landwirtschaft (BMEL).

Torres-Sánchez, J., López-Granados, F., Serrano, N., Arquero, O., \& Peña, J. M. (2015). HighThroughput 3-D Monitoring of Agricultural-Tree Plantations with Unmanned Aerial Vehicle (UAV) Technology. PloS One, 10(6), e0130479. https://doi.org/10.1371/journal.pone.0130479

Van der Meer, P.J. (1995). Canopy dynamics of a tropical rain forest in French Guiana. @wageningen, Landbouwuniv., Diss., 1995. S.1.

Vasilescu, M. M. (2013). Standard error of tree height using Vertex III. Bulletin of the Transilvania University of Brasov, 6(55)(2).

Wallace, L., Lucieer, A., Malenovský, Z., Turner, D., \& Vopěnka, P. (2016). Assessment of Forest Structure Using Two UAV Techniques: A Comparison of Airborne Laser Scanning and Structure from Motion (SfM) Point Clouds. Forests, 7(12), 62. https://doi.org/10.3390/f7030062 